\title{
Influence of Ni, Mo and Mn Content on the G-Phase Precipitation and Spinodal Decomposition of Aged Duplex Stainless Steels.
}

\author{
R.Badyka ${ }^{1}$, C.Pareige1, S.Saillet ${ }^{2}$ and C.Domain ${ }^{2}$ \\ 1. Groupe de Physique des Matériaux, UMR 6634 CNRS, Université et INSA de Rouen, Avenue de \\ l'université, St Etienne du Rouvray, France \\ 2. EDF R\&D Département Matériaux et Mécanique des Composants, Avenue des Renardières - \\ Ecuelles, Moret sur Loing, France
}

Duplex stainless steels (DSS) used in primary circuit of $2^{\text {nd }}$ generation nuclear power plant endure thermal ageing at service temperature $\left(285^{\circ} \mathrm{C}-325^{\circ} \mathrm{C}\right)$. It has been known for a very long time that these steels are prone to thermal ageing. The ageing impacts the mechanical properties (toughness decreases and hardness increases). The evolution of the mechanical properties depends on the DSS composition [1-4]. Mo-free grades which also contain a smaller amount of nickel than Mo-bearing ones were shown to age less $[1-3,5]$. The ageing of DSS steels is attributed to the decomposition of the ferrite: spinodal decomposition into regions enriched in iron $(\alpha)$ and regions enriched in chromium $\left(\alpha^{\prime}\right)$ and precipitation of G-phase particles enriched in $\mathrm{Ni}, \mathrm{Si}, \mathrm{Mn}$ and Mo. G-phase forms two type of particles: big TEM visible particles along dislocation lines or in the matrix after long annealing at temperature higher than $400^{\circ} \mathrm{C}$ and small (few nanometers) TEM invisible particles [6,7]. These latter were shown to appear at the $\alpha / \alpha^{\prime}$ interface by Atom Probe Tomography (APT) $[3,5,6]$.

The intensity of G-phase precipitation is much higher in Mo-bearing DSS than in Mo-free steels (with less G-forming elements) [5,8-10]. Also, spinodal decomposition was also shown to develop more importantly in Mo-bearing steels [3,9]. The literature [5,6,10] reports that the effective time exponent of the spinodal decomposition in Mo-bearing steels is close to $n=0.16$ as expected for spinodal decomposition [11]. In Mo-free steel, the effective time exponent was shown to be lower and equal to 0.07. The effective time exponent of phase transformation is strongly related to the diffusion mechanism and to vacancy path ways. Indeed, both interface diffusion [12] or mechanisms involving the diffusion of n-mers (small clusters) instead of monomers [13,14] are known to decrease time exponents. These diffusion mechanisms do not only influence development of spinodal decomposition but also the evolution kinetics of small G-phase precipitates. Indeed, the same effective time exponents were found for the evolution of the G-phase particle radius and the wavelength of the spinodal decomposition because of a kinetic synergy [5,9,15] between spinodal decomposition and G-phase precipitation. If the origin of these different effective time exponents is not understood yet, for sure it originates from the affinity between vacancies and solute species.

$\mathrm{Ni}$ has been shown to accelerate kinetics of spinodal decomposition in Fe-Cr-Ni model alloys [16,17]. In a lesser extent, Mn was also shown to have a similar effect in Fe-Cr-Mn alloys [17]. But in that respect, it is worth noting that:

- No kinetic study has been undertaken on these model alloys. Comparison of the microstructure was done at one aging time, one temperature. It is thus not known if kinetic enhancement is linked to an increase in the time constant $\mathrm{A}$ of the relationship $\lambda=\mathrm{At}^{\mathrm{n}}$ or in the time exponent i.e. if $\mathrm{Ni}$ or Mn contents can explain the difference in effective time exponent.

- Only ternary alloys were investigated preventing any conclusion on possible synergetic effects due to the presence of the different solutes on the kinetic of phase transformation to be drawn. 
- Influence of G-phase particles at the $\alpha / \alpha^{\prime}$ interfaces on the spinodal decomposition kinetic is not understood either.

In order to highlight and evidence the possible role of $\mathrm{Ni}, \mathrm{Mn}$ and $\mathrm{Mo}$ on the kinetics of phase transformation, Fe-Cr-Si-Ni-(Mo)-(Mn) model alloys with tuned composition (table 1) have been aged at $350^{\circ} \mathrm{C}$ up to $30000 \mathrm{~h}$ and $400^{\circ} \mathrm{C}$ up to $10000 \mathrm{~h}$. Kinetics of G-phase precipitation and spinodal decomposition were quantified using APT (LEAP 4000HR).

In this paper, we report on the influence of the different species on the appearance or not of the small Gphase particles, appearance of large G-phase particles without formation of prior small particles, on the time evolution of spinodal decomposition with composition in terms of effective time exponent and prefactor of the time law. A link is also done with micro-hardness measurements.

References:

[1] A. Trautwein, W. Gysel, Int. Cast Met. J. 6 (1981) p. 43.

[2] S. Bonnet et al, Mater. Sci. Technol. 6 (1990) p. 4221.

[3] H.M. Chung, T.R. Leax, Mater. Sci. Technol. 6 (1990) p. 4249.

[4] J.J. Shiao et al, J. Nucl. Mater. 217 (1994) p. 4269.

[5] C.Pareige et al J. Nucl. Mater. 465 (2015) p. 4383.

[6] F. Danoix, P. Auger, Mater. Charact. 44 (2000) p. 4177.

[7] Y. Matsukawa et al, Acta Mater. 116 (2016) p. 4104.

[8] M.K. Miller, J. Bentley, Mater. Sci. Technol. 6 (1990) p. 4285.

[9] F. Danoix, P. Auger, Mater. Charact. 44 (2000) p. 4177.

[10] C. Pareige et al, J. Nucl. Mater. 411 (2011) p. 490.

[11] K. Binder, D. Stauffer, Phys. Rev. Lett. 33 (1974) p. 41006.

[12] D. Huse, Phys. Rev. B. 34 (1986).

[13] K. Binder, D. Stauffer, Phys Rev Lett. 33 (1974) p. 41006.

[14] M. Athènes, P. Bellon, G. Martin, Acta Mater. 48 (2000) p. 42675.

[15] J. Emo et al, J. Nucl. Mater. 451 (2014) p. 4361-365.

[16] J.E. Brown, G.D.W. Smith, Surf. Sci. 246 (1991) p. 4285.

[17] P. Hedström et al, Mater. Sci. Eng. A. 574 (2013) p. 4123.

\begin{tabular}{|c|c|c|c|c|c|c|c|c|}
\hline \multirow{3}{*}{$\begin{array}{c}\text { Name } \\
\text { 8Ni-Si-Mo }\end{array}$} & \multicolumn{6}{|c|}{ Composition (wt\%) } & \multirow{2}{*}{\multicolumn{2}{|c|}{ Thermal ageing }} \\
\hline & \multirow{2}{*}{$\begin{array}{c}\mathrm{C} \\
0.03\end{array}$} & \multirow{2}{*}{$\frac{\mathrm{Cr}}{21}$} & \multirow{2}{*}{$\begin{array}{c}\mathbf{S i} \\
1\end{array}$} & \multirow{2}{*}{$\begin{array}{c}\mathbf{N i} \\
7.9\end{array}$} & \multirow{2}{*}{$\begin{array}{l}\text { Mo } \\
2.3\end{array}$} & \multirow{2}{*}{$\frac{\text { Mn }}{1}$} & & \\
\hline & & & & & & & $350^{\circ} \mathrm{C}$ & $400^{\circ} \mathrm{C}$ \\
\hline $10 \mathrm{Ni}-\mathrm{Si}$ & 0.04 & 21 & 1.1 & 10.4 & 0.01 & / & & \\
\hline 10Ni-Si-Mo & 0.04 & 20.9 & 1 & 10.4 & 2.5 & / & 1000h, & $500 \mathrm{~h}$ \\
\hline 10Ni-Si-Mn & 0.03 & 21.1 & 1 & 10.8 & 0 & 0.83 & $10000 \mathrm{~h}$ & $\begin{array}{l}5000 \mathrm{~h} \\
\text { and } 10000 \mathrm{~h}\end{array}$ \\
\hline 10Ni-Si-Mo-Mn & 0.03 & 20.4 & 1 & 10.5 & 2.4 & 0.79 & & \\
\hline
\end{tabular}

Table 1. Composition of the model alloys and the different ageing conditions 